\title{
Women's Employment Status and Mortality: The Atherosclerosis Risk in Communities Study
}

\author{
KATHRYN M. ROSE, Ph.D., ${ }^{1}$ APRIL P. CARSON, M.S.P.H., ${ }^{1}$ DIANE CATELLIER, Dr.Ph. ${ }^{2}$ \\ ANA V. DIEZ ROUX, M.D., Ph.D., ${ }^{3}$ CARLES MUNTANER, M.D., Ph.D., ${ }^{4}$ \\ HERMAN A. TYROLER, M.D., ${ }^{1}$ and SHARON B. WYATT, Ph.D. ${ }^{5}$
}

\begin{abstract}
Background: As women's labor force participation in the United States has increased over the past decades, there has been an interest in the potential health effects of employment. To date, however, research findings have been contradictory.

Methods: Thus, the aim of this study was to investigate the association between employment status and mortality among 7361 middle-aged African American and white women who participated in the Atherosclerosis Risk in Communities (ARIC) Study. Women were classified as employed or homemakers at the baseline examination (1987-1989) and were followed for approximately 11 years. Proportional hazards regression was used to estimate unadjusted and adjusted hazard ratios.

Results: After adjusting for sociodemographic factors and selected risk factors for mortality, employed women had a lower risk of mortality than homemakers (hazard ratio [HR] = $0.65,95 \%$ confidence interval $[C I]=0.49,0.86$ ). This decreased risk of mortality persisted in additional analyses that excluded those who died within the first 2 years of follow-up or, alternatively, those with a history of coronary heart disease (CHD), stroke, cancer, hypertension, diabetes, or a perception of fair or poor health at baseline. In cause of death-specific analyses, the mortality advantage among employed women persisted for circulatory systemrelated deaths; however, the association for cancer-related deaths was weaker, and the CI included one.

Conclusions: As the association between employment status and mortality was not explained by known risk factors for mortality, additional research is needed to identify other potential factors that may help to explain this relationship.
\end{abstract}

\footnotetext{
${ }^{1}$ Department of Epidemiology and ${ }^{2}$ Collaborative Studies Coordinating Center, Department of Biostatistics, School of Public Health, University of North Carolina at Chapel Hill, Chapel-Hill, North Carolina.

${ }^{3}$ Department of Epidemiology, University of Michigan, Ann Arbor, Michigan.

${ }^{4}$ Department of Epidemiology and Preventive Medicine, University of Maryland at Baltimore, Baltimore, Maryland.

${ }^{5}$ School of Nursing and School of Medicine, University of Mississippi Medical Center, Jackson, Mississippi.

The National Heart, Lung and Blood Institute supported this research under the following contracts and grants: N01-55015, N01-55016, N01-55017, N01-55018, N01-55019, N01-55020, N01-55021, N01-55022, and R01-HL064142.
} 


\section{INTRODUCTION}

W OMEN'S LABOR FORCE PARTICIPATION in the United States has steadily increased over the past decades. ${ }^{1}$ Both deleterious and protective effects of employment have been hypothesized. Some biomedical scientists proposed that increased labor force participation among women would contribute to higher rates of cardiovascular disease (CVD) in women, primarily mediated by increased levels of stress. ${ }^{2,3}$ In the social sciences, hypotheses have been proposed about both the deleterious and the protective effects of employment. The role strain model hypothesizes that employment negatively impacts women's health by causing role overload and conflict, 4,5 whereas the role accumulation/enhancement model argues that employed women would have a health advantage over full-time homemakers, as paid employment is a source of self-esteem, social support, and financial remuneration. ${ }^{5-7}$

The literature to date examining the association between women's employment status and CVD and mortality has been inconsistent. Reviere et al. ${ }^{8}$ reported homemakers were more likely to be diagnosed with coronary heart disease (CHD) than employed women. In contrast, there was no difference in the rate of diagnosed CHD between the employed women and homemakers in the Tecumseh Study, and self-reported occurrence of heart attacks was higher among homemakers than employed women. ${ }^{9}$ In addition, there was no difference in cardiovascular morbidity between employed women and homemakers over 15 years of follow-up in a study of HMO participants. ${ }^{10}$ Similarly, mixed findings for all-cause mortality have been reported. Hibbard et al. ${ }^{10}$ reported lower mortality among employed women compared with homemakers. Lower mortality for employed women was also reported in a longitudinal study of British women, with women employed part-time or in nonmanual jobs having a greater advantage. ${ }^{11}$ In a study of Wisconsin women, mortality was lower among employed women overall, although higher rates of mortality were reported among employed women in specific age and occupational strata (e.g., older women in white collar occupations) and causespecific mortality strata (e.g., accidental deaths among middle-aged women in labor occupations). ${ }^{12}$ Conversely, no difference was reported in the 19-year mortality of employed women compared with homemakers in a cohort of Cali- fornia women. ${ }^{13}$ These inconsistent findings warrant further investigation of the association between women's employment status and health.

Several studies have reported intriguing variations in the association between employment and health by socioeconomic status (SES) or position. In particular, a strong, protective effect of employment has been reported among the most socioeconomically disadvantaged groups (e.g., African American women, unmarried women), whereas more modest or no significant effects were found among the least disadvantaged groups (e.g., white women, married women). ${ }^{14,15}$ Historically, African American and unmarried women have had greater attachment to the labor force, as they tend to be employed for a greater portion of their adult years and contribute more substantially to the total family income compared with white or married women. ${ }^{16}$ Thus, among those with greater attachment to the labor force, the cumulative exposure to both the positive and the negative consequences of employment may be greater.

Inverse gradients between type of occupation and various health outcomes have been reported among men, ${ }^{17}$ but findings have not been consistent among women. ${ }^{11,13,15,18}$ The apparent absence of a gradient may be due to a more complex association between occupation and SES in women. ${ }^{19,20}$ At least historically, women have been segregated into occupations with limited mobility and received lower remuneration for paid work than men, even when in comparable jobs. ${ }^{21,22}$

The purpose of this study was to examine prospective associations of women's employment status with all-cause and cause-specific (circulatory system-related deaths, cancer, other) mortality and to determine if these associations, if extant, vary by sociodemographic factors or type of occupation.

\section{MATERIALS AND METHODS}

\section{Study population}

Participants were from the baseline examination of the Atherosclerosis Risk in Communities (ARIC) Study (1987-1989), a prospective study designed to investigate the etiology and natural history of atherosclerosis and CVD. Probability samples of men and women ages 45-64 years 
were selected from four U.S. communities: Forsyth County, NC; Jackson, MS; the northwest suburbs of Minneapolis, MN; and Washington County, MD. African Americans were oversampled in Forsyth County and sampled exclusively in Jackson. The ARIC Study protocol for the collection of data was reviewed and approved by the Institutional Review Boards at the participating institutions, and all participants gave informed, written consent prior to study participation and data collection. Response rates for the initial examination were $46 \%$ in Jackson and ranged from $65 \%$ to $67 \%$ in the other sites. ${ }^{23} \mathrm{~A}$ detailed account of the design and procedures ${ }^{24}$ has been reported.

Of nearly 16,000 ARIC participants at the baseline examination, we restricted our analyses to women $(n=8710)$. In addition, we excluded those with a race other than African American or white $(n=25)$ and African American participants residing in Minneapolis and Washington County $(n=26)$. Because we were interested in comparing employed women to homemakers, we also excluded those who were retired $(n=945)$, unemployed, disabled, temporarily out of the work force, or missing data on employment status $(n=$ 353). Thus, 7361 women remained for inclusion in this study.

\section{Ascertainment of employment and occupational status}

During the baseline examination, participants were queried about their current employment status. Participants were classified as employed if they indicated that they were currently working at a part-time or full-time job for pay. Homemakers included those who indicated that they were currently not working outside the home (but not retired, disabled, or unemployed).

Employed women were categorized into groups based on the Dictionary of Occupational Titles Classification used in the 1980 Census (managerial and professional specialties, $n=1532$; technical, sales, and administrative support, $n=$ 1947; service, $n=1230$; farming, forestry, and fishing, $n=15$; precision production, craft and repair, $n=141$; and operators, fabricators, and laborers, $n=537)$. Occupation-specific analyses excluded those participants missing occupational codes $(n=422)$ and, due to small numbers, those in farming, fishing, and forestry occupations.

\section{Ascertainment of deaths}

ARIC participants were contacted annually to ascertain vital status. If a participant was reported as deceased by next of kin or another designated contact person, the date and location of death, as well as any hospitalizations prior to death, were ascertained. When a participant was not located during annual follow-up, an attempt was made to determine vital status via search of hospital records and the National Death Index. Death certificates were obtained for virtually all deaths.

For this study, we included all deaths occurring through December 1999. International Classification of Disease (ICD) codes were used to classify the underlying cause of death into three broad categories (all CVD, cancer, and all other causes of death). Deaths occurring through 1998 were classified using ICD-9 codes: neoplasms (ICD-9 140-239), diseases of the circulatory system (ICD 390-459), and all other causes of death. Deaths occurring during 1999 were converted from analogous codes assigned using the ICD-10 codes: neoplasms (C00-D48) and circulatory system-related disorders (I00-I99).

\section{Ascertainment of covariates}

Sociodemographic information was obtained via self-report at baseline (1987-1989). Education was classified as less than a high school diploma, high school diploma, or at least some college. Annual family income was categorized into five groups (less than $\$ 16,000, \$ 16,000-24,999$, $\$ 25,000-34,999, \$ 35,000-49,999$, and greater than $\$ 50,000)$. Marital status, ascertained at the second ARIC examination (1990-1992), was categorized as married or unmarried.

Several health-related characteristics were also ascertained at the baseline examination. Participants were queried about a history of stroke, cancer, and CHD and were subsequently dichotomized for each condition based on their self-report and clinical evidence available at the baseline examination. Participants were also dichotomized based on their responses to questions about health insurance (yes, no) and medical visits for routine physical examinations at least yearly (yes, no). Smoking status was categorized as current, former, and never smoker. Alcohol use was categorized as current, former, and never drinker. Participants were queried about their perception of their general health compared 
with their peers and were categorized as fair/poor and excellent/good.

For the measurement of other physical and physiological health characteristics, standardized protocols and trained technicians were used, as well as quality control measures. Three sitting blood pressure (BP) measurements were taken, with the average of the second and third measurements used to determine BP. Hypertension was defined as systolic BP (SBP) $\geq 140 \mathrm{~mm} \mathrm{Hg}$, diastolic $\mathrm{BP}(\mathrm{DBP}) \geq 90 \mathrm{~mm} \mathrm{Hg}$, or use of hypertensive medications during the previous 2 weeks. Diabetes was defined as nonfasting glucose $>11.1 \mathrm{mmol} / \mathrm{L}(200 \mathrm{mg} / \mathrm{dl})$, fasting glucose $\geq 7 \mathrm{mmol} / \mathrm{L}(126 \mathrm{mg} / \mathrm{dl})$, self-reported history of diabetes, or current pharmacological treatment of diabetes. Measured height and weight were used to calculate body mass index (BMI) $\left(\mathrm{kg} / \mathrm{m}^{2}\right)$. High-density lipoprotein cholesterol (HDL-C) and low-density lipoprotein cholesterol (LDL-C) levels (mmol/L) were determined at the ARIC Central Lipid Laboratory using standardized methods. ${ }^{24}$

\section{Statistical analyses}

The age-adjusted prevalence and the age-adjusted means of health-related characteristics, by employment status, were obtained using logistic regression and general linear regression models, respectively, as implemented in a SAS macroprocedure. $^{25}$

Unadjusted and adjusted mortality hazard ratios (HRs) and 95\% confidence intervals (95\% CI) were obtained using Cox proportional hazards regression overall and separately for African American and white women. Effect modification of the employment status-mortality association by covariates was evaluated using an a priori significance level of 0.20 . Analyses were repeated, excluding those with early deaths and, alternatively, those with a history of CHD, stroke, cancer, hypertension, diabetes, or fair or poor health perceptions at the baseline examination. Additional regression analyses were performed for the association between type of occupation and mortality. Using homemakers as the referent group, indicator variables were created for each occupational category to obtain adjusted and unadjusted HRs. Analyses were also done assessing the association between employment status and each of three categories of causes of death (cancer, circu- latory, other). In these analyses, participants who died from causes of death not in the group being examined were treated as censored at the time of death.

All statistical analyses were performed using SAS version 8.2 software. $^{26}$

\section{RESULTS}

Table 1 presents sociodemographic and healthrelated characteristics of African American and white women in the ARIC Study by employment status. White women were more likely to be homemakers than were African American women. Among employed women, there was a marked variation in the distribution of types of job held by race. Specifically, only $16 \%$ of employed African American women were in technical, sales, and clerical jobs compared to $46 \%$ of white women. In contrast, $43 \%$ of African American women were in service-related occupations compared to only $13 \%$ of white women. Differences between African American and white women for other occupations were modest.

The sociodemographic and health profiles by employment status tended to be similar within racial groups. Compared to homemakers, employed women were on average younger and had higher education levels and family income. Additionally, employed women had modestly lower BMI and SBP and more favorable plasma LDL-C (white women only) and HDL-C levels than homemakers. They were also less likely to have a history of CHD, stroke, cancer (African American women only), or diabetes but more likely to report current use of alcohol. Homemakers were more than two times more likely to report fair or poor health status than were employed women. The proportion of women with health insurance coverage did not vary by employment status. Yearly visits to a physician were slightly more common among African American homemakers than employed women and slightly more common among white employed women than homemakers.

Over an average of 11 years of follow-up, 513 $(10 \%)$ of the women died. Cancer deaths were most common $(n=217)$, followed by all diseases of the circulatory system $(n=185)$. Diabetes $(n=$ 20) and chronic obstructive pulmonary disease (COPD) $(n=19)$-related deaths accounted for 
Table 1. Sociodemographic and Health-Related Characteristics of African American and White Homemakers and Employed Women in the ARIC Study, 1987-1989

\begin{tabular}{|c|c|c|c|c|}
\hline \multirow[b]{2}{*}{ Variable } & \multicolumn{2}{|c|}{$\begin{array}{c}\text { Homemaker } \\
\mathrm{n}=1958\end{array}$} & \multicolumn{2}{|c|}{$\begin{array}{l}\text { Employed } \\
\mathrm{n}=5403\end{array}$} \\
\hline & $\begin{array}{c}\text { African } \\
\text { American } \\
\text { women } \\
\mathrm{n}=426\end{array}$ & $\begin{array}{l}\text { White women } \\
\mathrm{n}=1532\end{array}$ & $\begin{array}{c}\text { African } \\
\text { American } \\
\text { women } \\
\mathrm{n}=1779\end{array}$ & $\begin{array}{l}\text { White women } \\
\mathrm{n}=3624\end{array}$ \\
\hline Age, years (mean \pm SD) & $54.5 \pm 5.9$ & $55.3 \pm 5.5$ & $52.3 \pm 5.3$ & $52.5 \pm 5.2$ \\
\hline Less than high school (\%) & 63.4 & 24.8 & 33.8 & 11.5 \\
\hline Family income $<\$ 25,000(\%)$ & 77.9 & 34.4 & 64.0 & 24.1 \\
\hline \multicolumn{5}{|l|}{ Type of occupation $(\%)$} \\
\hline Professional and managerial & & & 26 & 29 \\
\hline Technical, sales, and administrative support & & & 16 & 46 \\
\hline Service & & & 43 & 13 \\
\hline Farming, forestry, and fishing & & & 0 & 4 \\
\hline Precision production craft and repair & & & 3 & 3 \\
\hline Operators and laborers & & & 12 & 9 \\
\hline Married (\%) & 46.5 & 83.6 & 44.9 & 74.0 \\
\hline Body mass index ${ }^{a}$ (mean, $\mathrm{kg} / \mathrm{m}^{2}$ ) & 31.6 & 27.1 & 30.5 & 26.4 \\
\hline Systolic blood pressure ${ }^{\mathrm{a}}$ (mean, $\mathrm{mm} \mathrm{Hg}$ ) & 130.8 & 118.3 & 127.6 & 115.5 \\
\hline $\mathrm{HDL}^{\mathrm{a}}{ }^{\mathrm{a}}(\mathrm{mean}, \mathrm{mg} / \mathrm{dl})$ & 56.1 & 56.3 & 58.9 & 58.2 \\
\hline $\mathrm{LDL}^{\mathrm{a}}{ }^{\mathrm{a}}(\mathrm{mean}, \mathrm{mg} / \mathrm{dl})$ & 137.4 & 137.2 & 138.2 & 133.0 \\
\hline History of coronary heart disease ${ }^{\mathrm{a}}(\%)$ & 5.6 & 2.5 & 1.7 & 1.2 \\
\hline History of cancera $(\%)$ & 3.5 & 7.1 & 2.3 & 7.7 \\
\hline History of stroke ${ }^{a}(\%)$ & 5.0 & 1.4 & 0.9 & 0.6 \\
\hline Diabetic $^{\text {a }}(\%)$ & 30.1 & 10.5 & 17.1 & 6.4 \\
\hline Current smoker ${ }^{\mathrm{a}}(\%)$ & 25.6 & 23.7 & 23.4 & 24.5 \\
\hline Current alcohol user ${ }^{\mathrm{a}}(\%)$ & 17.3 & 52.7 & 21.2 & 66.3 \\
\hline Health insurance coverage $e^{\mathrm{a}}(\%)$ & 81.5 & 92.8 & 82.1 & 93.9 \\
\hline Visit physician yearlya $(\%)$ & 61.2 & 46.5 & 57.9 & 47.8 \\
\hline Perceived health status ${ }^{\mathrm{a}}(\%$ fair/poor) & 49.4 & 14.4 & 24.7 & 7.8 \\
\hline Mortality by $1999^{a}(\%)$ & 18.4 & 7.9 & 9.1 & 4.5 \\
\hline
\end{tabular}

adjusted for age.

the largest portion of deaths due to other causes $(n=111)$.

Table 2 presents HRs for the association between employment status and all-cause mortality by race. In age-adjusted models, both white and African American employed women had a strong, significantly lower hazard of mortality than homemakers. Associations did not change substantially after additionally adjusting for income, education, and marital status, nor was there a significant $(p<0.20)$ interaction between any of these sociodemographic factors and employment status. Additional adjustment for risk factors (SBP, use of antihypertensive medications, BMI, diabetes, cigarette smoking, alcohol use, physical activity, and HDL-C and LDL-C) and selected medical conditions (CHD, stroke, cancer) attenuated HRs, but a strong association persisted. Further adjustment for perceived health status and variables related to medical care (health insurance status and use of medical care) did not substantially influence the HRs. Because the findings did not differ markedly for African American and white women, further analyses were done for all women combined and adjusted for race.

Table 3 shows results of unadjusted and adjusted HRs for the association between employment status and mortality for the total population and several subgroups, excluding those participants with poor health profiles at baseline. For all women, the hazard of dying was markedly lower for employed women compared with homemakers $(\mathrm{HR}=0.48)$. Results from minimally adjusted models did not change appreciably after excluding participants who died within the first 2 years of follow-up $(n=48)$, had a history of stroke, cancer, or CHD at baseline $(n=630)$, or had a history of stroke, cancer, CHD, hypertension, or diabetes or perceived fair/poor health at baseline 
Table 2. All-Cause Mortality (Hazard Ratios and 95\% CI) Among African American and White Women by Employment Status. The ARIC Study

\begin{tabular}{|c|c|c|}
\hline \multirow[b]{2}{*}{ Model ${ }^{\mathrm{a}}$} & \multicolumn{2}{|c|}{$\begin{array}{l}\text { Hazard ratio } \\
(95 \% \mathrm{CI})\end{array}$} \\
\hline & $\begin{array}{c}\text { White women } \\
\mathrm{n}=5156^{\mathrm{b}}\end{array}$ & $\begin{array}{c}\text { African } \\
\text { American } \\
\text { women } \\
\mathrm{n}=2205^{\mathrm{b}}\end{array}$ \\
\hline Model 1 & $\begin{array}{c}0.45 \\
(0.36,0.56)\end{array}$ & $\begin{array}{c}0.40 \\
(0.31,0.53)\end{array}$ \\
\hline Model 2 & $\begin{array}{c}0.58 \\
(0.46,0.74)\end{array}$ & $\begin{array}{c}0.48 \\
(0.36,0.63)\end{array}$ \\
\hline Model 3 & $\begin{array}{c}0.49 \\
(0.36,0.67)\end{array}$ & $\begin{array}{c}0.56 \\
(0.38,0.83)\end{array}$ \\
\hline Model 4 & $\begin{array}{c}0.61 \\
(0.46,0.80)\end{array}$ & $\begin{array}{c}0.65 \\
(0.41,1.04)\end{array}$ \\
\hline Model 5 & $\begin{array}{c}0.61 \\
(0.42,0.88)\end{array}$ & $\begin{array}{c}0.67 \\
(0.41,1.10)\end{array}$ \\
\hline
\end{tabular}

aModel 1: unadjusted; model 2: adjusted for age and race; model 3: adjusted for variables in model 2 plus education, income, and marital status; model 4: adjusted for variables in model 3 plus SBP, hypertension medication use, BMI, diabetes, smoking status, alcohol use, physical activity, HDL-C and LDL-C, history of CHD, history of cancer, history of stroke; model 5: adjusted for variables in model 4 plus general health perception, health insurance coverage, and yearly physician visits.

$\mathrm{b}_{n}$ for various models varies due to missing data on covariates.

$(n=3497)$. After adjustment for risk factors, associations were generally attenuated but remained strong. A notable exception was the model that excluded those with a history of cancer, CHD, stroke, hypertension, diabetes, or perceived fair/poor health at baseline, where after adjustment for risk factors, the HR became stronger.

The occupations of employed women were classified using the Dictionary of Occupational Titles Classification from the 1980 Census (Table 4). Overall, the age-adjusted and race-adjusted cumulative mortality was highest among homemakers, intermediate among those with service and similar occupations, and lowest among those with professional/managerial occupations. In comparison to homemakers, each category of employed workers had a lower hazard of mortality. These associations were attenuated and tended to remain significant except in the fully adjusted models, where the CIs included one. There was not a clear gradient between the more desirable (management and professional) and lesser desirable (e.g., operators and laborers) occupational groups. In fact, the association was most favorable for operators and laborers $(\mathrm{HR}=0.52)$.

Table 5 presents HRs for the association between employment status and cause-specific mortality. In age-adjusted and race-adjusted models, employed women were less likely to die of circulatory system disorders, cancer, and all other causes. The magnitude of the association was weaker for circulatory-related deaths $(\mathrm{HR}=$ $0.46)$ and cancer-related deaths $(\mathrm{HR}=0.63)$ compared with all other causes of death (exclusive of cancer and circulatory-related) $(\mathrm{HR}=0.30)$. Adjustment for covariates slightly attenuated the strong associations for circulatory-related and other causes of death, whereas the association for cancer-related deaths was more modest and had a CI that included one.

\section{DISCUSSION}

In the current study, employed women had lower mortality than homemakers over approximately 11 years of follow-up. This association did not vary by race and persisted after adjusting for sociodemographic variables, chronic disease risk factors, and selected health conditions at baseline. Previous studies of employment status and mortality in women have reported a lack of association $^{9,13}$ increased mortality among selected subgroups of employed women (e.g., particular age and occupation groups) and for specific causes of death (accidents, cancer, and heart disease), ${ }^{12}$ and decreased mortality among employed women compared to homemakers. ${ }^{10,12,27}$ These inconsistent findings may be a reflection of methodological differences in the conceptualization of employment status, in the historical periods assessed, in the life stage at which employment status was ascertained, in the health outcomes evaluated, or in the sociodemographic characteristics of the cohorts studied.

The inconsistent findings may also reflect an inability to adequately assess other factors associated with obtaining paid employment. For example, the healthy worker effect is a phenomenon well documented in the epidemiological literature, whereby persons with more favorable health are more likely to enter and then persist in the labor force than those with less favorable health. ${ }^{28}$ It has been demonstrated in situations where workers, typically men, are compared with those who are not in the workforce because of 
Table 3. All-Cause Mortality (Hazard Ratios and 95\% CI) for the Association Between Employment Status and All-Cause Mortality. The ARIC Study

Hazard ratio $(95 \% \mathrm{CI})$

\begin{tabular}{|c|c|c|c|c|}
\hline \multirow[b]{2}{*}{ Model $^{\mathrm{a}}$} & \multicolumn{4}{|c|}{ Hazard ratio $(95 \%$ CI) } \\
\hline & $\begin{array}{l}\text { Total population } \\
\qquad \mathrm{n}=7361^{\mathrm{b}}\end{array}$ & $\begin{array}{c}\text { Subgroup 1: } \\
\text { Excluding those who died } \\
\text { within first } 2 \text { years } \\
\mathrm{n}=7313^{\mathrm{b}}\end{array}$ & $\begin{array}{c}\text { Subgroup 2: } \\
\text { Excluding those with a } \\
\text { history of CHD, cancer, or } \\
\text { stroke } \\
\mathrm{n}=6731^{\mathrm{b}}\end{array}$ & $\begin{array}{c}\text { Subgroup 3: } \\
\text { Excluding those with a } \\
\text { history of CHD, cancer, } \\
\text { stroke, hypertension, } \\
\text { diabetes or fair/poor health } \\
\text { status } \\
\mathrm{n}=3864^{\mathrm{b}}\end{array}$ \\
\hline Model 1 & $0.48(0.40,0.57)$ & $0.48(0.40,0.58)$ & $0.49(0.41,0.60)$ & $0.52(0.36,0.74)$ \\
\hline Model 2 & $0.53(0.44,0.64)$ & $0.54(0.45,0.66)$ & $0.54(0.44,0.66)$ & $0.56(0.38,0.81)$ \\
\hline Model 3 & $0.52(0.41,0.66)$ & $0.52(0.41,0.66)$ & $0.51(0.39,0.66)$ & $0.40(0.26,0.64)$ \\
\hline Model 4 & $0.58(0.44,0.75)$ & $0.58(0.44,0.75)$ & $0.53(0.40,0.70)$ & $0.38(0.24,0.61)$ \\
\hline Model 5 & $0.65(0.49,0.86)$ & $0.65(0.49,0.86)$ & $0.61(0.45,0.83)$ & $0.38(0.23,0.63)$ \\
\hline
\end{tabular}

${ }^{a}$ Model 1: unadjusted; model 2: adjusted for age and race; model 3: adjusted for variables in model 2 plus education, income, and marital status; model 4: adjusted for variables in model 3 plus SBP, hypertension medication use (except in Subgroup 3), BMI, diabetes (except in Subgroup 3), smoking status, alcohol use, physical activity, HDLC and LDL-C, history of CHD (except in Subgroups 2 and 3), history of cancer (except in Subgroups 2 and 3), history of stroke (except in Subgroups 2 and 3); model 5: adjusted for variables in model 4 plus general health perception, health insurance coverage, and yearly physician visits.

$\mathrm{b}_{n}$ varies in different models due to missing covariates.

disability or unemployment. Unlike men, a large percentage of women who do not work outside the home are homemakers. Different health profiles might be expected among homemakers than other groups of unemployed persons, as the implicit reason for not being employed is because of nonpaid familial responsibilities and not illness or disability per se. However, the social norms governing women's labor force participation have changed over past decades, and married women's labor force participation rates, which have typically been low, increased strongly in the later decades of the 20th century. With this shift of presumably healthy homemakers into the workforce, recent homemakers may represent a different group of women than in the past. Although some are not working because of family responsibilities, there is probably a larger proportion with psychological or physical morbidity, limited skills, or other barriers associated with lower labor force participation rates and higher levels of adverse health outcomes. There is some indirect evidence to support this. In the National Health Examination Survey (1960), employed women were on average 2 years older and had only a slightly higher level of educational attain-

Table 4. All-Cause Mortality (Hazard Ratios and 95\% CI) Among Categories of Workers and Homemakers for Association Between Type of Occupation and All-Cause Mortality

\begin{tabular}{lccccc}
\hline & $\begin{array}{c}\text { Cumulative } \\
\text { mortality }(\%)^{\mathrm{a}}\end{array}$ & Model 1 & Model 2 & Model 3 & Model 4 \\
\hline Managerial and professional & 4.9 & $0.44(0.33,0.59)$ & $0.53(0.35,0.80)$ & $0.60(0.38,0.93)$ & $0.73(0.45,1.18)$ \\
Technical and sales & 5.8 & $0.53(0.41,0.69)$ & $0.61(0.44,0.86)$ & $0.69(0.48,0.99)$ & $0.83(0.56,1.25)$ \\
Service & 6.2 & $0.58(0.45,0.75)$ & $0.56(0.40,0.77)$ & $0.64(0.44,0.93)$ & $0.73(0.49,1.08)$ \\
Precision and craft & 7.9 & $0.72(0.40,1.29)$ & $0.69(0.33,1.42)$ & $0.60(0.26,1.38)$ & $0.72(0.31,1.70)$ \\
Operators and laborers & 5.4 & $0.49(0.33,0.73)$ & $0.35(0.19,0.63)$ & $0.41(0.22,0.76)$ & $0.52(0.28,0.99)$ \\
Homemakers & 10.9 & 1.0 & 1.0 & 1.0 & 1.0 \\
\end{tabular}

adjusted for age and race.

${ }^{b}$ Model 1: adjusted for age and race; model 2: adjusted for variables in model 1 plus marital status, education, and income; model 3: adjusted for variables in model 2 plus SBP, hypertension medication use, BMI, diabetes, smoking status, alcohol use, physical activity, HDL-C and LDL-C, history of CHD, history of cancer, history of stroke; model 4: adjusted for variables in model 3 plus general health perception, health insurance coverage, and yearly physician visits. 
Table 5. Hazard Ratios (95\% CI) for Association Between Employment Status and Cause of Death. The ARIC Study, 1987-1989

\begin{tabular}{|c|c|c|c|}
\hline \multirow[b]{2}{*}{ Model $^{\mathrm{a}}$} & \multicolumn{3}{|c|}{ Cause of death } \\
\hline & $\begin{array}{c}\text { Disorders of the } \\
\text { circulatory system } \\
\mathrm{n}=185\end{array}$ & $\begin{array}{c}\text { Cancer } \\
\mathrm{n}=217\end{array}$ & $\begin{array}{c}\text { Other } \\
\mathrm{n}=111\end{array}$ \\
\hline Model 1 & $0.46(0.35,0.62)$ & $0.63(0.48,0.83)$ & $0.30(0.21,0.44)$ \\
\hline Model 2 & $0.50(0.37,0.68)$ & $0.72(0.54,0.96)$ & $0.35(0.24,0.51)$ \\
\hline Model 3 & $0.42(0.28,0.63)$ & $0.76(0.53,1.11)$ & $0.35(0.21,0.59)$ \\
\hline Model 4 & $0.53(0.34,0.83)$ & $0.72(0.50,1.05)$ & $0.38(0.23,0.64)$ \\
\hline Model 5 & $0.58(0.35,0.93)$ & $0.81(0.55,1.20)$ & $0.48(0.27,0.87)$ \\
\hline
\end{tabular}

${ }^{a}$ Model 1: unadjusted; model 2: adjusted for age and race; model 3: adjusted for variables in model 2 plus education, income, and marital status; model 4: adjusted for variables in model 3 plus SBP, hypertension medication use, BMI, diabetes, smoking status, alcohol use, physical activity, HDL-C and LDL-C for disorders of the circulatory system; adjusted for variables in model 3 plus BMI, smoking status, alcohol use, and physical activity for cancer; adjusted for variables in model 3 plus BMI, smoking status, alcohol use, physical activity, and diabetes for other cause of death; model 5: adjusted for variables in model 4 plus general health perception, health insurance coverage, and yearly physician visits.

ment than did homemakers. ${ }^{29}$ In contrast, in the National Health and Nutrition Examination Survey (1976-1980), employed women were on average 2 years younger and had a markedly higher level of education than did homemakers. ${ }^{29}$

There is some evidence suggesting that although increases in mortality and other adverse health outcomes may exist among homemakers, such increases are less pronounced than in other groups of women not employed outside the home. In the National Longitudinal Mortality Study, life expectancy was lower among both men and women not in the labor force compared with those employed, although the magnitude of difference was greater for men than for women. ${ }^{30}$ Furthermore, when the investigators categorized women not in the labor force by reason for not being employed (housework, unable to work), they found that the decrease in life expectancy between those employed and not working was smaller for homemakers than those ostensibly not working for other reasons. Others also report that whereas homemakers were more likely to report less favorable general health than were employed women, the increased risk was less pronounced than it was for women who were not working due to disability or unemployment. ${ }^{31}$

In this study, there were striking differences in the baseline socioeconomic and risk factor profiles of employed women and homemakers, which favored the former group. However, adjustment for these factors had only a modest impact on our findings. In an effort to address po- tential residual confounding, participants with an excess risk of mortality at baseline were excluded from subgroup analyses. Excluding those women who died within the first 2 years of follow-up or excluding those with prevalent CHD, stroke, cancer, diabetes, hypertension, or fair/poor health perception at baseline had minimal impact on our findings. Additionally, in some supplemental analyses, stratification by a number of variables associated with both employment status and mortality (age, educational attainment, perceived health status) yielded similar hazards of mortality across subgroups (data not shown).

Despite our efforts to address these methodological concerns in our analysis, we still cannot rule out that confounding due to risk factors or conditions not measured in our study may have affected a woman's choice to participate in the paid labor force and her subsequent risk of mortality. Unfortunately, we do not have measures that allow us to quantify the positive and negative effects of homemaking and paid employment that also may influence health. There are models that theorize that, like paid work, characteristics of homemaking related to psychological and physical demands, complexity, or independence may impact psychological functioning. ${ }^{32}$ In several studies, low autonomy ${ }^{33}$ and other characteristics of housework ${ }^{34-36}$ have been associated with higher rates of depression, independent of characteristics of paid employment. Depression and other forms of psychological distress have been linked with higher rates of mortality. ${ }^{37-39}$ As 
these characteristics represent potential mechanisms whereby homemakers may be at higher risk of mortality, the inclusion of assessments of psychological conditions could identify subgroups of homemakers who may be at higher risk of morbidity and mortality. Similarly, measurement of benefits/consequences of employment outside the home, such as income, social support, self-esteem, psychological and physical stress, could help identify mechanisms whereby paid employment potentially influences heath.

Census data indicate that employed African American and unmarried women contribute more substantially to the total family income than do white, married women. ${ }^{16}$ Accordingly, it is conceivable that those who contribute more heavily to the family income would have the greatest attachment to the labor force. Previous studies have reported a stronger association between employment status and hypertension between African American and/or unmarried women than among white or married women. ${ }^{15,29}$ In contrast, the current findings suggest that the association between employment status and mortality was similar for both African American and white women, and there was no effect modification by marital status.

Women in each occupational category had lower mortality than homemakers, although there was not a graded association by occupational status. These findings are consistent with other studies of women not reporting graded associations of health outcomes with occupational groups. ${ }^{13,15,18}$ Given the historical context at the time when these women entered the workforce, which was prior to the women's and civil rights movements, this might be expected. White women in this study were from a cohort of women who, on average, were less likely to be employed consistently across the life span, particularly if married, and to be in occupations not commensurate with their qualifications. Thus, their occupation might not be strongly related to their social status or economic well-being. In contrast, African American women from the same age cohort were on average more likely to be consistently employed across life. However, employment opportunities and financial remuneration were limited for these women from two southern U.S. communities. Although the women's movement and civil rights movement led to vast social changes during their years in the labor force, it is possible that any resultant benefits would be more limited in comparison to younger cohorts of women.

This study has several limitations that merit discussion. Patterns of labor force entry and exits 9 and extent of employment ${ }^{40,41}$ may impact employment associations between employment and health but could not be assessed in this study due to the use of a single measure of current employment status at middle age, with no differentiation between full-time and part-time employment. Likewise, there was no assessment of activities and time spent in completing housework for both homemakers and those employed outside the home, nor were other factors, such as household structure, assessed that could help in the differentiation of exposures. In the current as well as earlier studies, it was not possible to disentangle the potential contribution to mortality risk due to conditions that influenced selection into the paid labor force from those that resulted from employment status. This could only be done in a study of a cohort that includes sociodemographic and health measurements from childhood/adolescence (prior to labor force entry) as well as during adulthood.

The findings from this study are based on middle-aged women and may not be applicable to younger women, who are more likely to be actively involved in caring for children. Nonetheless, it is possible that some middle-aged women may be caring for dependent parents or grandchildren. Also, our findings must be considered in their historical context. Currently, two-income families are the norm, but this was not true during the period when these women entered the labor force. In fact, women are now more likely to be employed continually or for a greater portion of their adult life, and there is a wider range of opportunities available to women now than in the past. Thus, one would expect that the benefits and risks of paid work as well as the implications of being a homemaker might be different in younger cohorts of women.

This study has several strengths. Participants were from a large, community-based cohort of women, which included both white and African American women. The health and risk factor measures were measured in a standardized manner. Because of our large sample size, we were able to examine associations by cause of death, as well as among apparently healthy subsets of the population. 


\section{CONCLUSIONS}

In summary, employed women had markedly lower mortality than homemakers in this middleaged cohort. The lower mortality among employed women persisted across different types of occupation and was not explained by less favorable health profiles of homemakers. Still, we cannot exclude the possibility that health conditions not measured or adequately controlled for in our study affected participation in the paid labor force and mortality risk. Future studies that attempt to identify factors and conditions that influence selection into the labor force and quantify the health, material, and psychosocial consequences of paid employment and homemaking may provide clues to understanding the processes through which employment status influences mortality risk.

\section{ACKNOWLEDGMENTS}

We thank the staff and participants in the ARIC Study for their important contributions. We also thank Brigitt Heier for her assistance in preparing the manuscript.

\section{REFERENCES}

1. Bureau of the Census. Statistical Abstracts of the United States: 1990. Washington, DC: Government Printing Office, 1990.

2. Baruch GK, Biener L, Barnett RC. Women and gender in research on work and family stress. Am Psychol 1987;42:130.

3. Friedman M, Rosenman R. Type A behavior and your heart. New York: Knopf, 1974.

4. Sieber SD. Toward a theory of role accumulation. Am Sociol Rev 1974;39:567.

5. Barnett RC, Hyde JS. Women, men, work, and family. An expansionist theory. Am Psychol 2001;56:781.

6. Moen P. Women's roles and health: A life-course approach. In: Orth-Gomer K, Chesney MA, Wenger NK, eds. Women, stress and heart disease. Mahwah, NJ: Lawrence Erlbaum Associates, 1998.

7. Arber S, Gilbert G, Dale A. Paid employment and women's health: A benefit or source of role strain? $\underline{\text { Soc }}$ Health Illness 1985;7:375.

8. Reviere R, Eberstein IW. Work, marital status, and heart diseas. Health Care Women Int 1992;13:393.

9. Ebi-Kryston KL, Higgins MW, Keller JB. Health and other characteristics of employed women and home- makers in Tecumseh, 1959-1978. II. Prevalence of respiratory and cardiovascular symptoms and illnesses, mortality rates and physical and physiological measurements. Women Health 1990;16:23.

10. Hibbard JH, Pope CR. Effect of domestic and occupational roles on morbidity and mortality. $\underline{\text { Soc Sci }}$ Med 1991;32:805.

11. Weatherall R, Joshi H, Macran S. Double burden or double blessing? Employment, motherhood and mortality in the Longitudinal Study of England and Wales. Soc Sci Med 1994;38:285.

12. Passannante MR, Nathanson CA. Female labor force participation and female mortality in Wisconsin 1974-1978. Soc Sci Med 1985;21:655.

13. Kotler P, Wingard DL. The effect of occupational, marital and parental roles on mortality: The Alameda County Study. Am J Public Health 1989;79:607.

14. Rose KM, Newman B, Tyroler HA, Szklo M, Arnett D, Srivastava N. Women, employment status, and hypertension: Cross-sectional and prospective findings from the Atherosclerosis Risk in Communities (ARIC) Study. Ann Epidemiol 1999;9:374.

15. Rose KM, Newman B, Bennett T, Tyroler HA. Employment status and high blood pressure in women: Variations by time and by sociodemographic characteristics. Ann Epidemiol 1997;7:107.

16. Bureau of the Census. Current Population Reports. Washington, DC: Government Printing Office, 1980: Series P-60.

17. Rose G, Marmot MG. Social class and coronary heart disease. Br Heart J 1981;45:13.

18. O'Campo P, Eaton WW, Muntaner C. Labor market experience, work organization, gender inequalities and health status: Results from a prospective analysis of U.S. employed women. Soc Sci Med 2004;58:585.

19. Wright EO. Women in the class structure. Polit Soc 1989;17:1.

20. Liberatos P, Link BG, Kelsey JL. The measurement of social class in epidemiology. Epidemiol Rev 1988;10: 87.

21. Golden C. The emergence of "wage discrimination." Understanding the gender gap: An economic history of American women. NBER Series on Long-Term Factors in Economic Developmen. New York: Oxford University Press, 1990:83.

22. Golden $\mathrm{C}$. The gender gap in earnings and occupations. Understanding the gender gap: An economic history of American women. NBER Series on LongTerm Factors in Economic Development. New York: Oxford University Press, 1990:58.

23. Jackson R, Chambless LE, Yang K, et al. Differences between respondents and nonrespondents in a multicenter community-based study vary by gender ethnicity. The Atherosclerosis Risk in Communities (ARIC) Study Investigators. J Clin Epidemiol 1996; 49:1441.

24. The Atherosclerosis Risk in Communities (ARIC) Study: Design and objectives. The ARIC investigators. Am J Epidemiol 1989;129:687. 
25. Zhao DY. Logistic regression adjustment of proportions and its macro procedure. The SAS Users Group International Conference (SUGI) 22. San Diego, CA, 1998:1045.

26. Statistical analysis system. Version 8.2. Cary, NC: SAS Institute, Inc., 1989.

27. Long JA, Ickovics JR, Gill TM, Horwitz RI. Social class and mortality in older women. I Clin Epidemiol 2002;55:952.

28. Sterling TD, Weinkam JJ. The "healthy worker effect" on morbidity rates. I Occup Med 1985;27:477.

29. Rose KM. Women, work, and blood pressure: Variations in the employment status hypertension relationship across time, and by age, race and education. Doctoral dissertation. University of North Carolina at Chapel Hill, 1994.

30. Rogot E, Sorlie PD, Johnson NJ. Life expectancy by employment status, income, and education in the National Longitudinal Mortality Study. Public Health Rep 1992;107:457.

31. Stronks K, van de Mheen H, van den Bos J, Mackenbach JP. The interrelationship between income, health and employment status. Int J Epidemiol 1997;26:592.

32. Schooler C, Kohn M, Miller KA, Miller J. Housework at work. In: Schooler C, Kohn H, eds. Work and personality: An inquiry into the impact of social stratification. Norwood, NJ: Ablex Publishing Company, 1983.

33. Griffin JM, Fuhrer R, Stansfeld SA, Marmot M. The importance of low control at work and home on depression and anxiety: Do these effects vary by gender and social class? Soc Sci Med 2002;54:783.

34. Matthews S, Power C. Socio-economic gradients in psychological distress: A focus on women, social roles and work-home characteristics. Soc Sci Med 2002;54: 799.

35. Sogaard AJ, Kritz-Silverstein D, Wingard DL. Finnmark Heart Study: Employment status and parenthood as predictors of psychological health in women, 20-49 years. Int J Epidemiol 1994;23:82.
36. Bromberger JT, Matthews KA. Employment status and depressive symptoms in middle-aged women: A longitudinal investigation. Am J Public Health 1994;84:202.

37. Williams LS, Ghose SS, Swindle RW. Depression and other mental health diagnoses increase mortality risk after ischemic stroke. Am J Psychiatry 2004;161:1090.

38. Wassertheil-Smoller S, Shumaker S, Ockene J, et al. Depression and cardiovascular sequelae in postmenopausal women. The Women's Health Initiative (WHI). Arch Intern Med 2004;164:289.

39. Prescott E, Holst C, Gronbaek M, Schnohr P, Jensen G, Barefoot J. Vital exhaustion as a risk factor for ischaemic heart disease and all-cause mortality in a community sample. A prospective study of 4084 men and 5479 women in the Copenhagen City Heart Study. Int J Epidemiol 2003;32:990.

40. Rose KM, Newman B, Bennett T, Tyroler HA. The association between extent of employment and hypertension among women participants of the Second National Health and Nutrition Survey. Women Health 1999;29:13.

41. Nylen L, Voss M, Floderus B. Mortality among women and men relative to unemployment, part-time work, overtime work, and extra work: A study based on data from the Swedish twin registry. Occup Environ Med 2001;58:52.

Address reprints requests to: Kathryn Rose, Ph.D. Cardiovascular Disease Program University of North Carolina at Chapel Hill Bank of America Plaza, Suite 306 137 E. Franklin St. Chapel Hill, NC 27514

E-mail: kathryn_rose@unc.edu 
This article has been cited by:

1. Ann Hemingway. 2007. Determinants of coronary heart disease risk for women on a low income: literature review. Journal of Advanced Nursing 60:4, 359-367. [CrossRef]

2. May Blom , Anastasia Georgiades, Krisztina D. László , Hassan Alinaghizadeh , Imre Janszky , Staffan Ahnve . 2007. Work and Marital Status in Relation to Depressive Symptoms and Social Support among Women with Coronary Artery DiseaseWork and Marital Status in Relation to Depressive Symptoms and Social Support among Women with Coronary Artery Disease. Journal of Women's Health 16:9, 1305-1316. [Abstract] [PDF] [PDF Plus] 